Geograficando, vol. 13, n. ${ }^{\circ}$ 1, e019, junio 2017. ISSN 2346-898X

Universidad Nacional de La Plata.

Facultad de Humanidades y Ciencias de la Educación.

Departamento de Geografía

\title{
Urbanización neoliberal y resistencias sociales en la ciudad de Puebla
} Neoliberal urbanization and social resistances in Puebla City

\section{Mina Lorena Navarro*, Daniele Fini** y Diego Castro**}

*Instituto de Ciencias Sociales y Humanidades de la Benemérita Universidad Autónoma de Puebla, México | mina.navarro.t@gmail.com

**Instituto de Ciencias Sociales y Humanidades de la Benemérita Universidad Autónoma de Puebla, México

\section{PALABRAS CLAVE}

Urbanización

Neoliberalismo

Estado Nacional de

Competencia

Resistencias urbanas

KEYWORDS

Urbanization

Neoliberalism

National State of

Competence

Urban resistance

\section{RESUMEN}

En el presente artículo se exponen algunas claves para comprender las dinámicas de urbanización promovidas por el neoliberalismo en la ciudad de Puebla, en la región centro de México, a partir del análisis de algunas políticas recientes, como las de 1) privatización del servicio de agua; 2) despojo de tierras y reordenamiento del territorio en la zona de Angelópolis para la construcción de nuevos desarrollos inmobiliarios y; 3) mercantilización del patrimonio del Centro Histórico en función del sector turismo. Tales procesos se han dado en el marco de un conjunto de transformaciones de la economía de la ciudad, el rol del Estado y su relación con los capitales privados involucrados en ciertos proyectos de urbanización, lo que además ha generado una serie de luchas sociales que han buscado resistir a tales medidas.

\section{ABSTRACT}

In this article we present some clues to understand the dynamics of the urbanization promoted by the neoliberalism in Puebla, the centre area of Mexico, based on some recent policies, such as 1) the privatization of the water service; 2) land stripping and territory restructuring in the area of Angelopolis in order to build new real estate developments and; 3) the commodification of the Historic Centre patrimony due to tourism. Such processes have taken place as part of a group of transformations in the city economy, the role of the State and its relationship with the private capitals involved in certain urbanization projects; these have also generated a series of social struggles that have tried to resist such measures. 
En el presente artículo nos interesa presentar algunas claves para comprender las dinámicas de urbanización promovidas por el neoliberalismo en la ciudad de Puebla, vinculándolas con las principales transformaciones de la economía, el rol del Estado y su relación con los capitales privados, así como algunas de las respuestas sociales que se han activado para defender los ámbitos de vida que han buscado mercantilizarse. Realizamos este análisis a la luz de tres procesos de urbanización que han avanzado mediante la privatización de bienes y servicios públicos, la mercantilización del patrimonio histórico, el despojo de la tierra y el reordenamiento de los territorios para la construcción de nuevos desarrollos inmobiliarios urbanos. $\frac{1}{}$

En particular, nos referimos a la privatización del servicio de agua en la ciudad de Puebla a partir de 2013, cuando el Congreso Local de esta entidad aprobó la reforma a la Ley de Aguas incorporada al artículo 118 bis, propuesta por el gobernador Rafael Moreno Valle, que posibilitó que los organismos operadores de los municipios, como el Sistema Operador para los Servicios de Agua Potable y Alcantarillado del Municipio de Puebla (soapap), puedan dar en concesión el servicio a empresas privadas, que podrán fijar tarifas sin tener que pedir autorización al Poder Legislativo y contratar despachos externos para la cobranza y el embargo de morosos.

El segundo caso analizado es el reordenamiento territorial y el despojo de tierras de ejidatarios de la zona de Angelópolis, en la reserva Atlixcáyotl-Quetzalcóatl y zonas contiguas, al poniente de la ciudad de Puebla, con el fin de que un conjunto de empresarios locales y extranjeros construyeran nuevos desarrollos inmobiliarios, financieros y de servicios.

Y finalmente, la mercantilización del patrimonio del Centro Histórico de la ciudad de Puebla, a partir de una serie de iniciativas promovidas principalmente por el gobierno municipal, para desarrollar el sector turismo. Se trata de un proceso cuyas bases se asientan en el decreto de la unesco de 1987, que reconoce a la Zona de Monumentos Históricos como Patrimonio Cultural de la Humanidad, y se concreta mediante la puesta en marcha de diferentes planes municipales que, desde los años ochenta, han provocado la transformación urbanística del Centro Histórico y la valoración mercantil de su historia y arquitectura en función del desarrollo de la actividad turística, que hoy en día representa un sector importante de la economía local.

Figura 1. Mapa del estado de Puebla y de la ciudad de Puebla y sus municipios conurbados. También se señala la zona conocida como “Angelópolis”, elaborado por Mayeli Sánchez (2016) 


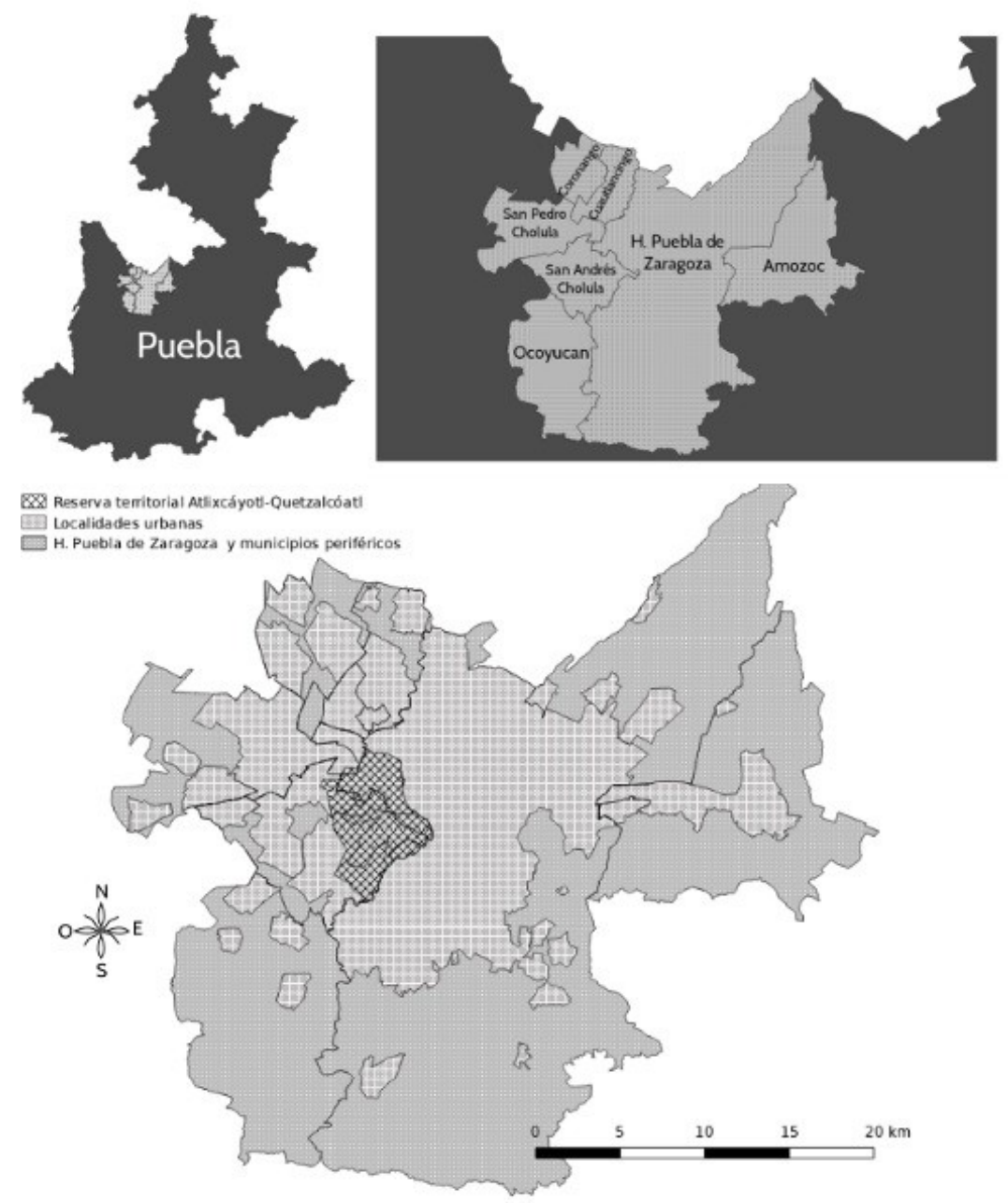

Fuente: INEGI Cierre de los Censos Económicos 2014. Denue 01/2015 y Vázquez, 2007

Antes de ahondar en la temática particular, cabe mencionar que una de las preocupaciones que motivó esta investigación se relaciona con la necesidad de abonar a los estudios críticos sobre la ciudad. Una de las razones es que, en la actualidad, más de 3.000 millones de personas, es decir, más de la mitad de la población mundial, vivimos en alguna ciudad (Fernández Durán, 2008). Lo que significa que, haciendo los cálculos correspondientes, en 2030, 60\% de la población será urbana, alcanzando su pico más alto en 2050, cuando llegue a los 10.000 millones de personas (Davis citado en Delgado, 2010). Sin duda, el horizonte de este crecimiento es insostenible, ya que a pesar de que las ciudades ocupan solamente el 3\% de la superficie del planeta (Fariña, 2015), dependen directamente de los combustibles fósiles, consumen 2/3 partes de la energía mundial y emiten $4 / 5$ partes de los gases de efecto invernadero, uno de los gases responsables del cambio climático (Newman et al., 2009, p. 4, citado en Delgado, 2010).

El acelerado crecimiento y propagación de las metrópolis en los últimos 50 años, profundizado por el neoliberalismo, respondió a la necesidad de expandir las relaciones monetarias y fijar un patrón de producción, distribución, cambio, consumo y desecho funcional a la reproducción del capital. Todo esto a costa del incremento de la sobreexplotación de la naturaleza y el trabajo vivo, relanzando reiteradamente procesos de acumulación originaria, con los que se han fracturado equilibrios vitales del metabolismo sociedad-naturaleza y despojado a poblaciones enteras de sus medios de sustento.

La reestructuración capitalista comenzada en los años setenta provocó la emergencia de importantes cambios, tanto en las formas de producción de la riqueza como en los mecanismos capitalistas de apropiación de plusvalía y generación de ganancias, bajo lo que Harvey (2004) ha denominado nuevo ciclo 
de acumulación por desposesión o despojo. Esta estrategia permitió la creación de nuevos circuitos de valorización a partir de la mercantilización de servicios públicos, bienes comunes, medios de existencia o esferas de la vida antes impensadas, como por ejemplo, el conocimiento tradicional, el material genético, el plasma de semillas y la biodiversidad en general.

Ciertamente, para la apertura de nuevos espacios de explotación los Estados están compitiendo por la radicación del capital global en sus territorios, desmantelando conquistas sociales que se habían conseguido después de intensos periodos de lucha, a fin de convertirlas en oportunidades de inversión. A su vez, en condiciones monopólicas y bajo reeditadas formas de violencia, las empresas transnacionales se están convirtiendo en los principales agentes y beneficiarios de este nuevo orden global (Composto y Navarro, 2012, p. 62).

En el caso de México, desde la década de 1980 comenzó a erosionarse de manera contundente el pacto social posrevolucionario, a partir de una serie de políticas que han posibilitado la participación de capitales nacionales y transnacionales en la gestión y el usufructo de la riqueza social, lo que propició la creciente concentración del poder de las corporaciones y la institucionalización de sus derechos. En suma, la ofensiva neoliberal ha venido reconfigurando la institucionalidad estatal y los modos de relación con el ámbito económico, dando lugar a la organización y el despliegue de estrategias cada vez más feroces de avasallamiento sobre los servicios y bienes públicos, así como a la agresión hacia ciertos ámbitos comunitarios y economías locales que, de manera tendencialmente autónoma, habían venido reproduciendo la vida social. $\underline{2}$

En el marco de estas profundas transformaciones, nos parece importante destacar algunas de las dinámicas promovidas de manera más relevante en las ciudades. Actualmente, la dimensión urbana —en particular a escala metropolitana - ha asumido un nuevo papel, porque representa un espacio estratégicamente importante para el despliegue de las iniciativas de neoliberalización (Peck, Theodore \& Brenner, 2009, p. 157); y, sobre todo, para volver a ser lo que la fábrica fue en la era fordista, es decir, el lugar donde se da la apropiación y el dominio capitalista, pero también el antagonismo y la lucha de clases (Hardt y Negri, 2011, p. 255). Entendemos que las ciudades son las espacialidades que ofrecen mejores condiciones geográficas y sociales para la producción y la reproducción de las relaciones capitalistas. Como comenta Harvey, el capital necesita de la urbanización para absorber el sobreproducto — de mercancías y mano de obra— que genera continuamente. "De ahí que surja una conexión íntima entre el desarrollo del capitalismo y el proceso de urbanización” (Harvey, 2013, pp. 21-22).

Sin duda, con el neoliberalismo las dinámicas de la urbanización han reorganizado las ciudades que, cada vez más, fungen como centros de comando y operación del capital financiero y corporativo (Sassen, 2004). A este respecto, nos parece importante retomar la noción de urbanización neoliberal de Neil Smith (2005) y su relación con la expansión del sistema financiero mundial en los años setenta. Este autor plantea que a partir de entonces la inversión extranjera directa dejó de estar dominada por capitales interesados exclusivamente en la extracción primaria, y que los mercados de capitales pasaron a tener mayor centralidad. Para dar cauce a este proceso se requirieron múltiples servicios empresariales auxiliares, además de buenas conexiones a las redes de comunicación y transporte mundial. En esa medida, el avance de estos imperativos fue reordenando los territorios a partir del impulso de proyectos de "renovación urbana”, megaproyectos y desarrollo de infraestructura, a costa de un crecimiento expansivo que ha ido absorbiendo antiguos barrios y urbanizando zonas rurales de cultivo y de conservación. Así, los bienes comunes del entorno rural y los bienes públicos de la ciudad comenzaron a ser concebidos como objetos de lucro y saqueo privado. Bajo esta lógica, el espacio urbano se fue convirtiendo en un campo de batalla donde se buscan conseguir los máximos beneficios de los diferentes usos aplicados al suelo. 
Conforme a esta dinámica, en México se ha buscado afianzar aquellos centros urbanos que cuentan con la infraestructura adecuada para "hacer negocios", como es el caso de las ciudades de México, Guadalajara, Monterrey, León, Cancún, Los Cabos, Puebla, Puerto Vallarta y la Riviera Maya (Villafranco, 2013). Para lograrlo se han tenido que cumplir ciertos requerimientos destinados a garantizar la prestación de servicios y la infraestructura tecnológica en medios de comunicación y de transporte aéreo y terrestre.

En ese sentido, la ciudad de Puebla constituye un ejemplo interesante para estudiar los procesos de urbanización neoliberal, pues en ella puede observarse el despliegue específico de tendencias generales que han sido documentadas en la literatura sobre el tema. A nivel nacional, Puebla es la sexta ciudad más poblada (IMCO, 2014), y está integrada a la "megalópolis del centro”, resultado de la “metropolización” de varias zonas y aglomeraciones urbanas en la región centro del país. Dicha delimitación abarca las zonas metropolitanas del valle de México, Puebla-Tlaxcala, Toluca-Lerma y las aglomeraciones de CuernavacaJiutepec, Cuautla y Pachuca (Flores González, 2002).

Figura 2. Mapa de la megalópolis del centro, elaborado por Mayeli Sánchez (2016)

\section{Ubicación geográfica de la megalópolis del centro}

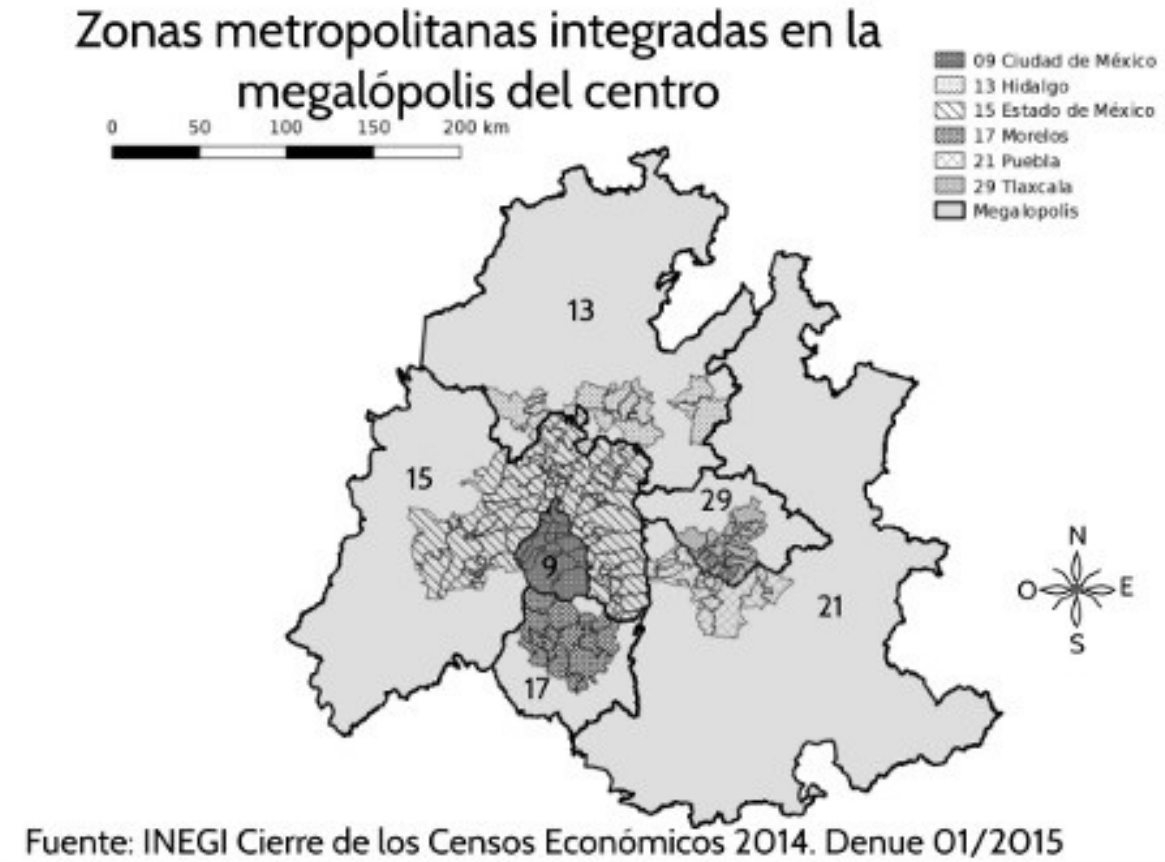


A continuación presentamos algunas claves para comprender las dinámicas de urbanización promovidas por el neoliberalismo en la ciudad de Puebla, enfatizando que han sido posibles gracias a una profunda reconfiguración de la economía y a ciertas intervenciones estatales favorables a la lógica de la acumulación del capital.

\section{Reconfiguraciones de la economía poblana en tiempos del neoliberalismo}

Una de las novedades de las políticas de apropiación de la riqueza en la llamada acumulación por desposesión, es que la generación de las ganancias de los capitalistas parece no proceder principalmente de la explotación de la fuerza de trabajo asalariada, sino de distintas dinámicas de despojo de bienes comunes naturales, privatización de bienes y servicios estatales, o de todas aquellas actividades que traen beneficios a partir de los derechos de propiedad intelectual (Harvey, 2004, pp. 118-119). Los estudios de Hardt y Negri proponen la hipótesis de que estamos en una fase de transición, en la que el papel central y hegemónico que ocupaba la producción industrial en el sistema capitalista, va siendo remplazada por la producción biopolítica (2011, p. 145). Esta categoría hace referencia a un conjunto de nuevas y distintas actividades, ligadas sobre todo al sector servicios y a la producción de bienes inmateriales, en las cuales la determinación del valor depende cada vez más de elementos inmateriales y sociales, y la explotación no se da principalmente sobre la cooperación de los trabajadores asalariados en los lugares de producción sino como explotación biopolítica sobre la cooperación social del trabajo y la vida de la gente al interior de las metrópolis (2011, p. 151).

Un primer dato que nos permite acercarnos a los cambios recientes en la economía de la ciudad de Puebla es el número de trabajadores ocupados por sector. A partir de los años setenta, momento en que la industria textil — principal motor económico de la región- entró en crisis, se asistió al constante aumento de los empleados en el sector terciario y a la disminución de los empleados en el sector secundario (Cuadro 1), a pesar de que la producción industrial sigue manteniendo un papel porcentual importante en la generación del producto interno bruto (inegi, 2014). Es de resaltar que, desde mediados de los años ochenta, en todos los informes y planes de desarrollo de los gobiernos municipal y estatal el turismo aparece como un sector económico importante y hacia el cual dirigir esfuerzos institucionales.

Tabla 1. Porcentaje de trabajadores empleados en Industria y Terciario (elaboración propia) (INEGI, 1970, 2001, 2014).

\begin{tabular}{|l|l|l|l|l|}
\cline { 3 - 5 } \multicolumn{2}{c|}{} & $\mathbf{1 9 6 9}$ & $\mathbf{1 9 9 8}$ & $\mathbf{2 0 1 3}$ \\
\hline \multirow{2}{*}{ Puebla (Estado) } & Industria & $17,5 \%$ & $38,8 \%$ & $27,4 \%$ \\
\cline { 3 - 5 } & Terciario & $21,7 \%$ & $58,5 \%$ & $69,6 \%$ \\
\hline \multirow{2}{*}{ Puebla (Municipio) } & Industria & $36,7 \%$ & $24,4 \%$ & $19,8 \%$ \\
\cline { 3 - 5 } & Terciario & $50,6 \%$ & $58,4 \%$ & $76,2 \%$ \\
\hline
\end{tabular}

De acuerdo con lo que propone e interpreta Harvey, en Puebla se asistió a la multiplicación de inversiones capitalistas para la apropiación de bienes colectivos y servicios públicos, como forma de acumulación por desposesión. En particular, en el estudio que hicimos sobre las políticas de despojo y reordenamiento territorial de Angelópolis, ha sido curioso notar que varios de los capitalistas que invirtieron en los proyectos de expansión urbana en esta parte de la ciudad son exempresarios del sector textil. Dichas iniciativas de inversión arrancaron a mediados de los años ochenta con la compra de tierras en buena medida reguladas por 
la figura de la propiedad social. $\underline{3}$ Cabe mencionar que este proceso local se correspondió con una política más amplia de apropiación propiciada por la reforma del artículo 27 constitucional, que abrió la posibilidad a la enajenación de tierras comunales y ejidales, mediante el dispositivo jurídico de la expropiación, sustentado en la retórica de la utilidad pública, es decir, en su justificación como de interés general. La venta y expropiación de tierras en Angelópolis fue acompañada por prácticas violentas como el engaño, el robo y la represión gubernamental, y los empresarios implicados contaron con la complicidad de instituciones estatales.

Asimismo, la privatización del servicio de agua potable en 2014 representa otro ejemplo paradigmático de las dinámicas de acumulación por desposesión. En este sentido, la necesidad de recursos hídricos por parte de los procesos de expansión urbanos ha generado conflictos en localidades periurbanas debido a que los vecinos se oponen a la perforación de nuevos pozos o a la apropiación de fuentes hídricas, a partir de los cuales ciertos entes estatales pretenden llevar agua a los nuevos fraccionamientos exclusivos de Angelópolis.

Si la perspectiva de acumulación por desposesión propuesta por Harvey nos permite observar algunas de las dinámicas de apropiación capitalista de la riqueza desarrolladas en Puebla en estos años, la hipótesis de Hardt y Negri sobre la explotación biopolítica nos puede dar claves para entender algunos elementos de novedad en las dinámicas económicas de la ciudad. En particular, queremos evidenciar el papel central que juegan los elementos inmateriales en la determinación de los precios de las mercancías y los servicios o, en otras palabras, la reconfiguración de la explotación como explotación biopolítica y la reconfiguración de la apropiación capitalista como expropiación del común.

A este respecto, la trasformación del Centro Histórico en función de la industria del turismo también resulta paradigmática. En este caso, las ganancias son generadas por las actividades relacionadas con este sector, a partir de elementos como la historia, la hermosura del paisaje urbano y la arquitectura, el clima social y cultural de un barrio; elementos difíciles de medir en los cálculos de los economistas y difíciles de ser apropiados bajo la forma de propiedad privada. Normalmente, dichos elementos aparecen en los cálculos económicos como externalidades (Hardt y Negri, 2004, p. 178), es decir, como factores que si bien no participan directamente en la producción de una mercancía o servicio, sí lo hacen en la determinación de su precio. Harvey se refiere a ellos como "capital simbólico colectivo" (2013, p. 156). Hardt y Negri, por su parte, sostienen que hoy en día el conjunto de estos elementos -el común- representa tanto el producto como la condición, no sólo de la industria turística, sino también de la producción capitalista misma. Estas consideraciones llevan al planteamiento de una hipótesis según la cual la urbanización es un proceso de producción continua de un bien común (Harvey, 2013, p. 125), esto es, que genera las condiciones para la acumulación capitalista que se da mediante la apropiación privada de tal bien común.

Las primeras iniciativas políticas relacionadas con el turismo en el Centro Histórico y la urbanización de Angelópolis provocaron cambios en el precio de tierras e inmuebles. El Plan Parcial del Centro Histórico de la ciudad de Puebla de 1982, que dio inicio a las transformaciones urbanísticas dirigidas a valorizar el patrimonio del Centro, determinó un aumento de los precios de los inmuebles, generando, a su vez, un incremento de la rentabilidad inmobiliaria y la expulsión de habitantes pobres. Mientras que el reordenamiento territorial de Angelópolis dio lugar a una dinámica de especulación inmobiliaria, debida al alza de los precios de los terrenos próximos a las nuevas infraestructuras que se planeaba construir.

Así, nuestro estudio sobre la vinculación del Centro Histórico con el turismo ha mostrado cómo las iniciativas gubernamentales han buscado construir cierta imagen de la ciudad, una que la vuelva atractiva tanto para la inversión como para el disfrute de la industria turística y cultural. Por un lado, a partir de la búsqueda del reconocimiento de entes internacionales y la publicidad, y por el otro, mediante la remodelación del paisaje urbano, que ha implicado la restauración de edificios, la expulsión de familias pobres y la reubicación o el cierre de mercados públicos. En el caso de los nuevos fraccionamientos dirigidos 
a las clases altas en Angelópolis, se ha mostrado que elementos inmateriales, como la seguridad de la zona en un territorio controlado y suficientemente apartado, determinan los altos precios de los inmuebles.

Para resumir, durante el neoliberalismo en Puebla se han podido observar tendencias similares a las identificadas por los estudios sobre las trasformaciones del capitalismo, en particular, a partir de los planteamientos de la acumulación por despojo y la emergencia de la producción biopolítica. Si estas dinámicas hablan de la expansión de los procesos de valorización y apropiación capitalista en cada vez más ámbitos sociales y espaciales, los casos abordados en este texto muestran cómo dichas dinámicas se han vuelto posibles gracias a la intervención directa de los entes gubernamentales. Los planes municipales y estatales en especial, el Programa de Desarrollo Regional de Angelópolis, así como la legislación nacional reformada en los años noventa (artículo 27 constitucional, Ley Nacional de Aguas, etcétera), generaron las condiciones para permitir fructíferas inversiones capitalistas en los sectores inmobiliario, comercial y financiero en Angelópolis, en el sector turismo en el Centro Histórico y en el servicio de suministro de agua potable en la ciudad de Puebla.

\section{Relación entre actores público-estatales y capitales privados en los procesos de urbanización en Puebla}

Son diversos los trabajos que han analizado las reconfiguraciones del Estado en el neoliberalismo. En este texto nos distanciamos de aquellas perspectivas que consideran que el neoliberalismo dio lugar a un Estado mínimo o débil, pues, por el contrario, entendemos que el papel de las instituciones públicas resulta fundamental para el proceso de acumulación capitalista, en tanto colaboran legal, simbólica y violentamente con el avance de los flujos de capital que, a nivel global, se movilizan para mercantilizar servicios públicos, bienes comunes, medios de existencia o esferas de la vida no plenamente subsumidas a la lógica del valor.

¿A qué responde este comportamiento estatal? El politólogo alemán Joachim Hirsch sostiene que existe una estrecha conexión entre el surgimiento del Estado burgués y el despliegue del capitalismo. Así, en relación con las características del comportamiento estatal posfordista sugiere la existencia de un "Estado Nacional de Competencia”, es decir, un Estado cuyas estructuras internas son determinadas por la competencia internacional y sus ventajas comparativas.

De manera que el "Estado nacional competitivo" es un Estado fuertemente intervencionista, tanto económica como socialmente; aunque su política ya no se enfoca en la corrección de las desigualdades propias de las economías capitalistas, como proponía el proyecto fordista haciendo referencia a la existencia de un Estado protector o de bienestar. Ahora su finalidad prioritaria es la movilización selectiva de las fuerzas sociales para la competencia internacional y la represión de aquellos intereses que se contrapongan a ésta, lo último, hasta por la fuerza; en consecuencia, la política estatal promueve la profundización de las desigualdades y las divisiones sociales (Moreno, 2001).

En América Latina la urbanización se encuentra signada por la autoconstrucción popular y consecuentemente, en general, por la ausencia de una planificación vinculada al crecimiento habitacional de las grandes ciudades. En su mayoría, las políticas públicas implementadas por los Estados están retrasadas con respecto, primero, a las necesidades de vivienda y, luego, a los servicios básicos necesarios para la población. Así lo evidencian los déficits habitacionales, que en las principales ciudades del continente han permanecido incambiados durante décadas, especialmente en sus periferias. La ciudad de Puebla no escapa a esta ley general, aunque el caso de urbanización estudiado no cumple el mismo patrón, ya que el Estado intervino directamente a través de los planes municipales y estatales de desarrollo.

En particular, el proceso de urbanización de Angelópolis requirió el establecimiento de una alianza entre gobierno y capital, similar a la analizada por Neil Smith (2005) en sus estudios sobre la urbanización 
neoliberal en la ciudad de Nueva York. Uno de los elementos que llama su atención es la alianza entre el gobierno neoyorkino y el capital, puesta de manifiesto en una exoneración fiscal de 900 millones de dólares destinada a que la Bolsa de Valores permaneciera en la ciudad y de la cual se adelantó la mitad para la construcción de una nueva y lujosa sede que alojara al capital financiero de Wall Street.

De la misma forma que en el caso estudiado por Smith, es posible afirmar que en el proceso de urbanización de Angelópolis los gobiernos estatal y municipal otorgaron una subvención indirecta a los capitales que participaron en el negocio, implementando medidas legales destinadas a cambiar el uso de tierra, de rural a urbana, o a expropiar ejidos sin cumplir con las obligaciones legales y pagando por debajo de lo establecido. Las tierras fueron posteriormente transferidas a empresarios locales y años después sirvieron para la construcción de barrios privados, un club de golf, centros educativos, comerciales y financieros, a lo que se agregaron rápidos accesos a las carreteras que conectan con la Ciudad de México y Veracruz, haciendo de Angelópolis el lugar de vida de las clases acomodadas de Puebla y los estados vecinos. Hasta comienzos de 1990, cuando iniciaron las acciones de despojo, dichas tierras producían alimentos y eran territorio vital de los pueblos cholultecas. 4

Algo similar sucedió con la concesión del servicio de agua potable, pues el consorcio beneficiado recuperó la inversión licitatoria inicial en menos de tres años, cuando el negocio le fue otorgado por 60 años (Maldonado y Campos, 2016). La licitación fue ganada por Aguas de México, que transfirió el derecho a un consorcio creado días antes, Agua Puebla para Todos, situación amparada por el marco legal mexicano. Este consorcio, que actualmente gestiona la concesión del servicio de agua, está integrado por empresas nacionales y extranjeras, así como por un fideicomiso bancario. El grupo de abogados encargado de la transacción se encuentra vinculado a la financiera norteamericana J. P. Morgan, principal empresa financiera de Estados Unidos, también relacionada con el mercado de alimentos en Europa. En ese sentido, podemos decir que:

El Estado ha fungido como un dispositivo jurídico-político que facilita la entrada del capital global, esto es, el despliegue de una gestión que incursiona en ámbitos básicos de la vida, como lo es el acceso el agua, para convertir un bien vital para la existencia humana en un recurso mercantil susceptible de ser explotado y vendido al mejor postor (Maldonado \& Campos, 2016, p. 20).

En cuanto a la implementación de la industria turística, la investigación no ha evidenciado relaciones o facilitaciones directas entre aparatos estatales y empresarios particulares. En cambio, hemos notado que esta industria pudo desarrollarse sólo a partir de múltiples iniciativas promovidas por los gobiernos municipal y estatal, que impulsaron un proceso de “patrimonialización” Histórico. Entre dichas iniciativas se incluyen el decreto de reconocimiento como patrimonio cultural de la humanidad de la unesco, las remodelaciones del paisaje urbano y la publicitación del lugar.

Así, el comportamiento estatal poblano puede comprenderse en un marco más general, esto es, como parte de un proceso global tendiente a colocar a las instituciones públicas y los gobiernos como agentes promotores, facilitadores y ejecutores de la acumulación capitalista en las ciudades. La larga lista de acontecimientos vinculados a la privatización del agua y a la urbanización de Angelópolis conecta de manera imbricada a gobernadores y mandos medios municipales y estaduales con promotores privados, empresarios y capitales transnacionales, integrando a las familias poblanas más poderosas. Ello no debe impedirnos reconocer un fenómeno global de mutación profunda de las funciones estatales ocurrido desde el comienzo del proceso de neoliberalización en la década de 1970.

Volviendo al argumento de Hirsch, se configuró una forma estatal contrastante con el Estado de seguridad fordista, que presuponía la "institucionalización burocrática” del conflicto entre clases y, en consecuencia, 
mecanismos para la negociación y la regulación con participación de las partes. Esto llevó a que existiera un fuerte control estatal de los procesos económicos y sociales. El Estado de competencia, en cambio, renunció a las estrategias de integración material: "en lugar de la normalización, estandarización e igualación burocrática, el individualismo, la diferencia y la libertad de mercado desencadenada se convierten en los valores dominantes” (1996, p. 67).

En Puebla, el Estado y sus diferentes esferas de expresión se encuentran lejos de ser instituciones reguladoras de los diferentes intereses, es decir, encargadas de corregir desigualdades e injusticias. En su expresión concreta, el Estado es un activo agente del proceso de acumulación y reproducción del capital. Ciertamente, las intervenciones del Estado en las dinámicas de urbanización de la ciudad de Puebla se relacionan con fenómenos globales y no pueden entenderse sólo a partir de la peculiaridad local. Como hemos indicado anteriormente, lejos está de ser el Estado mínimo de la ideología neoliberal, pero también lo está de ser el Estado protector del fordismo. La caracterización desarrollada por Hirsch (1996) en relación con el comportamiento estatal posfordista, al que denomina Estado Nacional de Competencia, se adecua claramente a la realidad mexicana y, en particular, al proceso de urbanización poblano mencionado.

Las formas de operación del Estado para hacer posible la mercantilización y el despojo de los medios de vida y territorios, a partir de lo que denominamos dispositivo expropiatorio, no han estado exentas de una serie de resistencias sociales que han impugnado el orden dominante y, en algunos casos, han buscado generar alternativas colectivas y comunitarias para cuidar y regenerar la vida ante la degradación y el colapso socioambiental.

\section{Resistencias urbanas}

En años recientes, varios estudiosos han advertido de la importancia de las metrópolis como escenario central de la lucha de clases. Estas propuestas parten de una crítica a aquellas tradiciones del marxismo y del movimiento obrero que consideraban que el terreno exclusivo de la lucha era el interior de la relación capitalista de explotación. En este sentido, buscamos ir más allá de este planteamiento, considerando que la dinámica de la explotación de clase no se limita a los lugares de producción de mercancías; por el contrario, conviene ubicar el conjunto de prácticas predatorias y de despojo, que ponen en entredicho la calidad de la vida cotidiana de las poblaciones urbanas, en los ámbitos de reproducción de la vida social (Harvey, 2013, pp. 189-190).

A este respecto, coincidimos con las perspectivas de Harvey (2013), y de Hardt y Negri (2011), quienes ubican la dimensión urbana como un terreno en el que se organizan novedosas y estratégicas formas de producción y apropiación de la riqueza social para garantizar la acumulación del capital; terreno en el que, al mismo tiempo, se concretan y expresan importantes procesos de lucha y antagonismo social contra y más allá de los lugares de producción. Así, consideramos que las ciudades no sólo son el epicentro de la acumulación del capital, sino también un terreno de lucha e incluso de subversión de los procesos de despojo, explotación y expansión continua de la valorización del valor. De ahí que nos parezca relevante rastrear y analizar la emergencia y la multiplicación de diversos procesos de lucha y resistencia que, de múltiples maneras, han rechazado e impugnado el despliegue de las políticas de neoliberalización en las ciudades, por sus efectos de degradación y devastación sobre la vida.

La investigadora Fernanda Paz ha registrado al menos 81 conflictos socioambientales en la "megalópolis del centro" (Paz, 2016). Desde nuestra perspectiva éstos expresan la disputa entre el capital-Estado y variados sujetos comunitarios en torno al control, acceso y gestión de aquellos territorios y medios o fuentes de vida que han garantizado el sustento y hecho posible la reproducción de la vida humana y no humana, así como una intensificación y expansión de las fronteras de cierto tipo de extracción, producción, circulación, 
consumo y desecho de la riqueza social convertida en mercancía para garantizar la acumulación del capital (Navarro y Fini, 2016, p. 10).

Entre los conflictos sociales detonados por proyectos de urbanización en la ciudad de Puebla se encuentra la resistencia del Comité del Pueblo Unido en Defensa de la Tierra, los Recursos Naturales y Nuestras Raíces, surgido en 1994 para oponerse a la construcción del Anillo Periférico, un parque industrial y el Centro Comercial Angelópolis. Durante los años noventa esta organización se volvió un importante referente que denunció los efectos socioambientales y los procesos de despojo en los espacios periurbanos o todavía rurales de la periferia de la ciudad de Puebla, producto de la metropolización, vía la urbanización y la implementación de otros proyectos de inversión de los sectores inmobiliario, comercial y financiero (Castro, 2015).

Otro caso es el de la lucha social contra la concesión del servicio de agua potable a empresas privadas, que en 2014 dio nacimiento a la Asamblea Social del Agua en la que se aglutinan al menos 30 Comités Ciudadanos en Defensa del Agua en la ciudad de Puebla. El trabajo realizado por esta red de colectivos desde entonces se ha encauzado hacia la lucha contra la privatización del agua mediante la organización de acciones informativas, la formación interna, la denuncia y el encuentro entre los vecinos de las colonias afectadas, la defensa legal y la concertación de amparos contra las altas tarifas del agua, la articulación y la coordinación con otros procesos de resistencia a nivel local y nacional, así como de la implementación de estrategias colectivas para el emprendimiento de alternativas que incluyen proyectos de captación de agua de lluvia o huertos comunitarios (Navarro, 2016).

En suma vemos que, ante las políticas neoliberales de despojo, explotación, cercamiento, privatización y mercantilización de los ámbitos de vida y medios de existencia, a nivel regional y nacional están emergiendo múltiples procesos de resistencia. Éstos se están acuerpando para conservar, cuidar y regenerar la vida ante la degradación y el colapso socioambiental que se expresa de manera profundamente crítica en los espacios urbanos metropolitanos actuales. ${ }^{6}$ Muchos de los ámbitos que hoy se encuentran en el blanco de los proyectos de inversión del capital son, a la vez, la base que garantiza las condiciones para la reproducción de la vida de las comunidades directamente ocupadas en su gestión y cuidado, y que asegura el sustento de otros segmentos de la población. Tal es el caso de las zonas de conservación, que brindan beneficios ecosistémicos, y de las economías campesinas de la zona surponiente de Puebla, que proporcionan alimentos al resto de la población.

\section{Conclusiones}

En síntesis, en las dinámicas de urbanización neoliberal en Puebla observamos una configuración local de las tendencias globales del neoliberalismo. En este sentido, hay elementos para pensar que esta tendencia global también se encuentra en expansión en Puebla y que las ganancias capitalistas ya no provienen principalmente de la producción de mercancías en fábricas, sino de procesos de despojo, mercantilización y privatización (tierras o servicio de agua) y de actividades relacionadas con el sector servicios (servicios financieros o turismo), donde los elementos inmateriales adquieren cada vez más importancia en la determinación y apropiación del valor.

Los actores estatales han jugado un papel protagónico en la implementación de las recientes transformaciones en la economía y la urbanización en la ciudad de Puebla. En contraste con el mito del Estado disminuido de la ideología neoliberal, resulta evidente la intervención directa de los gobiernos municipal y estatal en la promoción de cambios dirigidos a atraer y favorecer dinámicas de acumulación capitalista, según un patrón documentado por la literatura, que Hirsch denomina "Estado Nacional de Competencia". 
Finalmente, la lucha de clases se extiende fuera de los lugares de producción de mercancías y de los ámbitos de explotación laboral, desplegándose en la defensa de los ámbitos y medios naturales, materiales y sociales que garantizan la reproducción de la vida. En esa medida, las luchas de la ciudad son estratégicas para frenar la lógica de saqueo y lucro de la urbanización neoliberal, así como para experimentar y sostener alternativas colectivas y comunitarias capaces de cuidar y regenerar la vida ante la degradación y el colapso socioambiental que enfrentamos y que se expresa de manera profundamente crítica en los espacios urbanos metropolitanos actuales.

\section{Notas}

1 Este trabajo es parte de la investigación "Ecología política y conflictos socio-territoriales en la ciudad de Puebla”, apoyada por el Programa para el Desarrollo Profesional Docente, Secretaría de Educación Pública y la buap.

$\underline{2}$ En otros trabajos hemos desarrollado la noción de dispositivo expropiatorio para comprender las diversas estrategias que empresas y gobiernos emplean para despojar a las poblaciones de sus medios de existencia y sus territorios. Esta variedad de estrategias involucra procesos que podrían leerse como una suerte de continuum, en que la violencia — tanto material como simbólica — va in crescendo a medida que se pasa de una figura a otra, develando poco a poco la verdadera naturaleza del Estado como garante de la acumulación de capital: 1) legalidad institucional; 2) consenso y legitimidad; 3) cooptación y captura; 4) disciplinamiento y normalización; 5) criminalización; 6) represión; 7) militarización y contrainsurgencia (Composto y Navarro, 2014, pp. 57-58).

$\underline{3}$ Con propiedad social se hace referencia a una forma de posesión colectiva de la tierra por parte de grupos de campesinos implementada a partir de la Revolución Mexicana a inicios del siglo xx. Ésta es reconocida legalmente en el artículo 27 de la Constitución, hasta su reforma, que en 1992 abrió la posibilidad a la enajenación de estas tierras y a su parcelización en la forma de la propiedad privada.

$\underline{4}$ Poblaciones nahuas descendientes de los pueblos prehispánicos asentados en Cholula.

$\underline{5}$ Con este término se hace referencia a aquellas acciones que transforman algo en patrimonio, es decir, que lo dotan de valor histórico, cultural y/o artístico.

6 El investigador Víctor Toledo denuncia que hay al menos 420 conflictos socioambientales en México (Enciso, 2016), relacionados con cuestiones agrícolas, biotecnológicas, energéticas, forestales, hidráulicas, mineras, de residuos peligrosos y rellenos sanitarios, turísticos y urbanos (Toledo, 2015, p. 60).

\section{Bibliografía}

Castro, U. (2015). Condición metabólica del trabajo e imágenes religiosas en las configuraciones del capital y la naturaleza. El caso conurbado en la ciudad de Puebla en el siglo xxi (Tesis de doctorado en sociología inédita). buap Instituto de Ciencias Sociales y Humanidades.México

Composto, C. y Navarro, M. L. (Comps.). (2014). Territorios en disputa. Despojo capitalista, luchas en defensa de los bienes comunes naturales y alternativas emancipatorias para América Latina. México: Bajo Tierra Ediciones.

Delgado, G. C. (2010). Ordenamiento territorial, bioeconomía urbana y pobreza frente al cambio climático. 
En Delgado, G. C., Gay, C., Imaz, M. y Martínez, M. A. (Coords.), México frente al cambio climático: retos y oportunidades. México: unam.

Enciso, A. (16 de febrero de 2016). Hay en México 420 conflictos socioambientales. La Jornada. Recuperado de: http://www.jornada. unam.mx/2016/02/10/sociedad/038n1soc

Fariña Tojo, J. (28 de junio de 2015). Una ciudad más próxima. El País. Recuperado de http://internacional.elpais.com/internacional/2015/06/25/actualidad/1435226184 302194.html

Fernández Durán (2008). Planeta de metrópolis (en crisis). Madrid: Ecologistas en Acción.

Flores González, S. (2002). La Megalópolis de la región Centro de México: una aproximación a su análisis. Puebla: buap/ Colegio de Tlaxcala.

Hardt, M. y Negri, A. (2004). Multitud. Guerra y democracia en la era del Imperio. España: Ed. Debate.

Hardt, M. y Negri A. (2011).Commonwealth, El proyecto de una revolución del común. Madrid: Akal.

Harvey, D. (2004). El nuevo imperialismo. Madrid: Akal.

Harvey, D. (2013). Ciudades rebeldes. Del derecho de la ciudad a la revolución urbana. Madrid: Akal.

Hirsch, J. (1996). Globalización, capital y Estado. México: uam-x.

inegi (1970). Censo general de población 1970. México: inegi.

inegi (2001). Censos económicos 1999 (Tomo I). Puebla. México: inegi.

inegi (2014). Censos económicos 2014. Puebla. México: inegi.

Instituto Mexicano para la Competitividad (2014). ¿Quién manda aquí? La gobernanza de las ciudades y el territorio en México. México: IMCO. Recuperado de: http://imco.org.mx/wpcontent/uploads/2014/09/20140909 LibroCompleto Indice de Competitividad Urbana 2014.pdf

Maldonado, C, y Campos, B. (2016). La mercantilización del agua potable como parte de la urbanización del capital en la ciudad de Puebla. Inédito.

Moreno, K. (2001). Entrevista a Joachim Hirsch. Revista Herramienta, 16. Recuperado de: http://www.herramienta.com.ar/revista-herramienta-n-16/entrevista-joachim-hirsch

Navarro, M. L. (en imprenta). Hacer común contra la fragmentación en la ciudad. Experiencias de autonomía urbana. Puebla: buap- icsyh.

Navarro, M. L. y Fini, D. (Comps.). (2016). Despojo capitalista y luchas comunitarias en defensa de la vida en México. Claves desde la Ecología Política. Puebla: buap- icsyh.

Neil, S. (2005). El redimensionamientode las ciudades: la globalización y el urbanismo neoliberal. En David Harvey y Neil Smith, Capital financiero, propiedad inmobiliaria y cultura. Barcelona: macba / uab,Universitat Autònoma de Barcelona.

Paz Salinas, M. F. (2016). Conflictos socioambientales y megalópolis: paradojas y desafíos. Ponencia presentada en el $2^{\circ}$ Coloquio Internacional: Las paradojas de la Mégalópolis. Gobernar el agua, el aire y el territorio. México: cesop.

Peck, J., Theodore, N. y Brenner, N. (2009). Neoliberal Urbanism: Models, Moments, Mutations. Ensais Review, XXIX(1), 49-66. 
Pérez Winter, C. (2013). Patrimonialización, turistificación y autenticidad en Exaltación de la Cruz, Argentina. Estudios y Perspectivas del Turismo, Vol. 22 Nro. 4, Buenos Aires.

Sassen, S. (2004). La ciudad global: introducción a un concepto. En The Crown Fountain, 51-62.

Recuperado de: https://www.bbvaopenmind.com/wp-content/uploads/static/pdf/050 SASKIA SASSEN.pdf

Toledo, V. (2015). Ecocidio en México. La batalla final es por la vida. México: Grijalbo.

Villafranco, G. (26 de mayo de 2013). Las 10 mejores ciudades para hacer negocios. Revista Forbes..

Recuperado de: http://www.forbes.com.mx/las-diez-mejores-ciudades-para-hacer-negocios/ 